\title{
O REI ESTÁ NU: desaprendendo e entendendo os tempos em que eu vivo
}

\author{
Djalma Thürler ${ }^{1}$ \\ Duda Woyda ${ }^{2}$
}

Resumo: No presente ensaio, os autores tentam se livrar de algumas tecnologias textuais impostas à academia e lançam-nos em uma incursão epistêmica pautada na articulação entre uma dimensão contrapedagógica e queer-decolonial para pensarem como os a[r]tivismos e a própria arte pautam algumas implicações decoloniais. Seu intuito é investigar como a aposta decolonizadora, baseada na problemática de violência de gênero e a permanente colonialidade do poder e do saber como forma de dominação, podem gerar saberes de desaprendizagens insurgentes que fraturam o modelo colonial tornando possível outras formas de produção subjetiva.

Palavras-chave: Saberes de desaprendizagem; Decolonialidade; Gênero.

\section{EL REY ESTÁ UN: desaprendiendo y entendiendo los tiempos en que vivo}

Resumen: En el presente ensayo, los autores intentan deshacerse de algunas tecnologías textuales impuestas a la academia y nos lanzan en una incursión epistémica pautada en la articulación entre una dimensión contra-pedagógica y queer-decolonial para pensaren como los a[r]tivismos y el propio arte pautan algunas implicaciones decoloniales. Su intención es investigar cómo la apuesta decolonizadora, basada en la problemática de violencia de género y la permanente colonialidad del poder y del saber como forma de dominación, pueden generar saberes de desaprendizajes insurgentes que fractura el modelo colonial haciendo posible otras formas de producción subjetiva.

Palabras-clave: Saberes de desaprendizaje; Decolonialidad; Género.

\section{Introdução}

MARTHA - Quando eu tiver filhos, quero que eles cresçam como mato no jardim.

Todo mundo ignora o mato e ele cresce forte, alto. As rosas, cheias de cuidados, dão flores cada vez mais raquíticas.

Aí, numa primavera, nem isso. Claro - estão mortas.

"O despertar da primavera", de Frank Wedekind

"Vocês sabem que nós, pobres artistas, temos de nos mostrar, de vez em quando, à sociedade, para fazer lembrar ao público que não somos selvagens” (WILDE, 2012, p. 12), por isso aceitamos o convite dos editores para participar deste dossiê. À época, estávamos às voltas com a produção do espetáculo teatral "Que os outros sejam o Normal", peça adulta em que discutíamos questões acerca do desvio - caminhos outros - e da norma, à luz dos saberes de desaprendizagens, esse "conjunto de saberes e disposições políticas “empreendidos por feministas, gays, lésbicas, negros e negras, ou por sujeitos e grupos que rejeitam rótulos e títulos têm emergido questões, práticas, experiências que ousam

\footnotetext{
${ }^{1}$ Doutorado em Letras pela Universidade Federal Fluminense. Vice-Coordenador Acadêmico do IHAC da Universidade Federal da Bahia. Professor permanente do Programa Multidisciplinar de PósGraduação em Cultura e Sociedade. Mestre em Ciência da Arte (UFF) e Bacharel em Artes Cênicas e em Pedagogia, pela Universidade Federal do Estado do Rio de Janeiro (UNI-RIO).

${ }^{2}$ Doutorando do Programa Multidisciplinar de Pós-Graduação em Cultura e Sociedade da Universidade Federalda Bahia - UFBA.

${ }^{3}$ O espetáculo estreou em 28 de setembro de 2018, no Teatro Vila Velha, em Salvador (BA), com texto e direção de Djalma Thürler e com Duda Woyda e Mariana Moreno no elenco.
} 
subverter modos de vida e noções consagradas" (LOURO, 2012, p. 364), que desafiam o monopólio de heranças clássicas de verdades únicas, masculinas, heterossexuais e brancas da Ciência e das Artes. (THÜRLER, 2018a, p. 14.).

Esse dispositivo tem sido utilizado, primeiramente, para discutir a aparente ideia de normalidade e naturalidade que moldaram/moldam a sociedade brasileira em seus aspectos culturais-identitários, notadamente, o modelo "heteropatriarcal, colonial e neonacionalista, que visa desfazer as conquistas de longos processos de emancipação operária, sexual e anticolonial dos últimos séculos" (PRECIADO, 2018, p. 11) e algumas relações sociais como a "homofobia, o racismo, o sexismo, o heterossexismo, o classismo, o militarismo, o cristianocentrismo, o eurocentrismo, [que] são todas ideologias que nascem dos privilégios do novo poder colonial capitalista, masculinizado, branqueado e heterossexualizado" (GÓMEZ; GROSFOGUEL, 2012, p. 343).

Nesse sentido, o catolicismo ou a "teo-política del conocimiento" (GROSFOGUEL, 2007, p. 63), "esse grande pilar da vida brasileira, queira-se ou não" (TREVISAN, 2007, p. 397), foi um poderoso condutor social que assumiu o controle da produção de conhecimentos - e do próprio saber filosófico - e que conformou a ordem natural das coisas, disseminado valores que ainda hoje são pautas das macro e das micropolíticas, haja vista as declarações da atual ministra dos Direitos Humanos, da Igualdade Racial e das Mulheres, Damares Alves, que afirmara que o modelo ideal de sociedade é aquele em que as mulheres deveriam ficar apenas em casa, possivelmente para desempenhar o papel social para o qual teriam nascido, o de mãe ${ }^{4}$. A pastoraministra, defensora da "família tradicional brasileira", em seus pronunciamentos, confere à mulher papel antigo, submisso e dependente, passando ao largo das conquistas contemporâneas, como a liberdade sexual, a opção da maternidade, as novas práticas de contracepção e a legalidade do aborto, apenas para citar alguns temas da agenda do feminismo contemporâneo, essa

[...] revolución políticocultural, producto de la modernidad y del progreso de la humanidad; un movimiento producido, desarrollado y liderado por las mujeres, cuyos primeros estallidos ocurren en Europa, cuna de la civilización, y resurge con nuevos bríos a mediados del siglo $\mathrm{XX}$ en los Estados Unidos (máxima potencia imperial), para luego expandirse al resto del mundo no occidental. Esta revolución cultural es entendida como deseada y necesaria para el bien de todas 'las mujeres'

\footnotetext{
${ }^{4} \mathrm{http}$ //www.esquerdadiario.com.br/Modelo-ideal-de-sociedade-e-com-mulheres-apenas-em-casa-dizpastora-cotada-para-ministra?fbclid=IwAR1jjYKqDQ7NQPSctE5zQrqXn3BtOp1cH8gwV_VJB6KbYuwfw_uh-h3q68. Acesso em: 30/12/2018.
} 
dado el sistema universal de dominación y, dado que aún hay amplias regiones del mundo donde aún no ha iniciado, las feministas provenientes de o en relación con las regiones más adelantadas del mundo desarrollado- debemos trabajar arduamente en su expansión (MIÑOSO, 2016, p. 143-144).

Simone de Beauvoir, filósofa e escritora francesa, com o contundente " $\mathrm{O}$ Segundo Sexo" (BEAUVOIR, 1960), lançava, à época de sua publicação, matrizes teóricas importantes desse feminismo, resultando em sua célebre frase "não se nasce mulher, mas torna-se mulher", o que Jorge Drexler, capturou mais tarde, em 2010, com a canção "Tres mil millones de latidos", quando indagou: "O mar se move a lua, /Ou a lua as marés. /É o que se nasce /Ou será que o que é criado. /Estou confuso aqui”.

Se é o que se nasce, ou será aquilo que se cria é um dos elementos radicais de resistência micropolítica em tempos de contrarrevolução (PRECIADO, 2018, p. 12), da politização mesma das identidades, porque faz

[...] recolocar o debate no campo do social, pois é nele que se constroem e se reproduzem as relações (desiguais) entre os sujeitos. As justificativas para as desigualdades precisariam ser buscadas não nas diferenças biológicas (se é que mesmo essas podem ser compreendidas fora de sua constituição social), mas sim nos arranjos sociais, na história, nas condições de acesso aos recursos da sociedade, nas formas de representação (LOURO, 2007, p. 21).

E, ao recolocar o debate nesses termos, refuta o determinismo biológico que reservava às mulheres, por exemplo, o destino social de serem mães, anjos tutelares, guardiãs da fé, orientadoras dos filhos e transmissoras da tradição, misteriosas, complexas e com sexualidade difusa, "em oposição ao homem, focado na sexualidade genitalizada" (LOURO, 2017, p. 14). Assim, gênero e sexualidade começavam, então, a ser compreendidos como construção social, que designava o lugar das mulheres na sociedade e na família, e isto é, historicamente, a principal causa da dominação do sexo masculino sobre o sexo feminino.

Há pouco tempo, em 2016, a carioca Juliana Reis confrontou uma dessas "verdades" naturalizadas e maldisse sobre o papel da maternidade respondendo em sua página no Facebook a um desafio sobre a beleza e o dom divino da maternidade, mas, ao invés de compartilhar fotos felizes, Juliana relatou seus sentimentos mais intensos sobre sua experiência, como podemos observar: 
FIGURA 1 - Reprodução do jornal “O Extra”, de 17/02/16

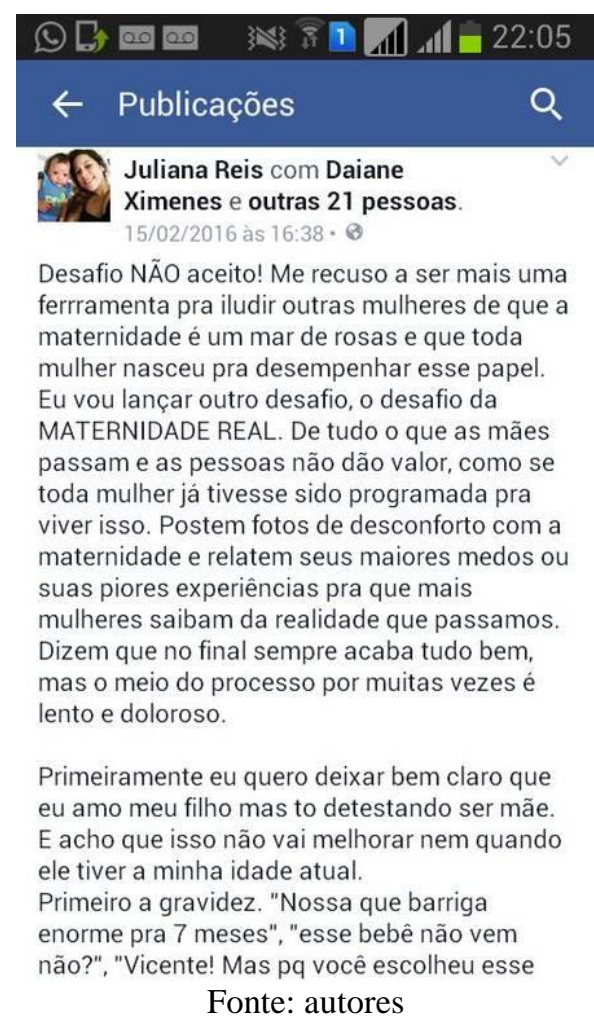

Ao reprogramar o desafio da "maternidade real", pedindo que outras pudessem, também, desmontar esse aprendizado cultural, o de que toda mulher teria nascido para desempenhar - cordata - o papel de mãe, Juliana reanima a máxima da luta política das mulheres francesas, nos anos 1970: "un enfant, si je veux, quand je veux". No post de Juliana,

[...] a ideia é [foi a de] desconstruir essa coisa de que mãe tem que ter algumas atitudes para ser uma boa mãe. Por exemplo, que 'mãe que é mãe precisa gostar de amamentar'. Eu não gosto de amamentar, meu filho fica colado 24 horas por dia no meu peito e é cansativo, é doloroso. Gosto em alguns momentos, mas falar que morro de amores não dá. Muitas mulheres passam por isso e não têm coragem de falar (REIS, Juliana, 2016, sp).

A recusa do que convencionalmente atribuiu-se à maternidade no post de Juliana mostra que a normatividade nem sempre está assegurada, ao contrário, "las leys que intentam regular y excluir invariablemente producen ideales fantasmales necessariamente inestables y ambivalentes" (BUTLER, 2011, p. 13), por isso, as normas precisam ser experimentadas cotidianamente dando ênfase à produção dos sujeitos. Daí a surpresa do post em tela, que colabora para subverter a subordinação, 
opressão e dominação de gênero inscritas e reiteradas nos seus corpos há muitos anos e, ao mesmo tempo, possibilita questionar a categoria "mulheres", abraçando a tarefa decolonial de reinterpretar a história e as potencialidades de um devir mulher.

\section{Jogos de poder, resistências e escapes}

O post anterior é um exemplo claro das brechas, das maneiras de resistir e ressignificar as normas que avançam, hoje, desarticulando a estrutura de poder colonial, esse modo mais geral de dominação no mundo atual, entendido por Quijano como a "colonialidade do poder", que produziu - e ainda produz - as discriminações sociais codificadas como "raciais", "étnicas", de "gênero" ou "sexuais", de acordo com os momentos, os agentes e as populações envolvidas. Estas construções intersubjetivas, um produto da dominação colonial pelos europeus, foram consideradas como fenômenos naturais e não da história da sociedade, "uma pretensa naturalidade [que] oculta o caráter construído e continuamente reiterado dessas marcas" (LOURO, 2017, p. 10), uma estrutura de poder dentro da qual outras relações sociais operam muitas vezes com violência, a única forma de garantia do controle sobre territórios e corpos, e de corpos como territórios. Nesta perspectiva,

[...] homens e mulheres adultos contam como determinados comportamentos ou modos de ser parecem ter sido 'gravados' em suas histórias pessoais. Para que se efetivem essas marcas, um investimento significativo é posto em ação: família, escola, mídia, igreja, lei participam dessa produção. Todas essas instâncias realizam uma pedagogia, fazem um investimento que, frequentemente, aparece de forma articulada, reiterando identidades e práticas hegemônicas enquanto subordina, nega ou recusa outras identidades e práticas [...]. $\mathrm{Na}$ constituição de mulheres e homens, ainda que nem sempre de forma evidente e consciente, há um investimento continuado e produtivo dos próprios sujeitos na determinação de suas formas de ser ou 'jeitos de viver' sua sexualidade e seu gênero. (LOURO, 2000, p. 16-17. Grifo nosso).

Essa pedagogia de gênero (LOURO, 2017, p 37), a nosso ver, se aproxima do que Rita Segato denomina pedagogia da crueldade (SEGATO, 2018, p. 11), estratégia de reprodução do sistema que são os atos e práticas que ensinam, habituam e programam os sujeitos a transmutar o vivo e sua vitalidade em coisas, uma espécie “coisificação da vida", uma pedagogia 
se pense que o destino daquela pessoa não é o seu. É uma programação que começa nos exércitos. Uma pessoa que chega ao exército, em qualquer país, a primeira coisa que precisa aprender é a se estruturar de forma psicopática, no sentido de que o destino de meu inimigo não é o meu. Essa programação que existia para os exércitos, está sendo passada para toda a sociedade. Se matam você, tudo bem. Mas, nunca a mim. E, no entanto, poderia ser eu. Mas, esse poderia ser eu, que além do mais é muito curioso, porque é uma das bases do cristianismo, não faça ao outro o que não gostaria que fizessem a você, não está na rota de leitura dos evangelhos, nos fundamentalismos cristãos de hoje. Essa parte do humanismo eu a resgato, não só como política, trata-se de uma chave para a sobrevivência da espécie. No entanto, o fundamentalismo o fecha, e cria um 'nós' e 'os outros', com uma barreira intransitável (SEGATO, 2017, sp).

Esse endurecimento, a que se refere Segato, produz um efeito de normalização, de banalização da crueldade e isso promove a diminuição da empatia dos sujeitos, fator inescapável a esse "projeto de nação" (MISKOLCI, 2012), ou seja, a crueldade apreendida conforme formulado por Clément Rosset (2004) - habitual das relações humanas contemporâneas, principalmente as de gênero, hierárquicas e binárias, é diretamente proporcional, por um lado, às formas de gozo narcísico e consumista e, por outro, ao isolamento dos cidadãos mediante sua desestabilização. E, assim, nesses jogos em que o poder é exercido "muitas vezes com cumplicidade e malícia, eventualmente com violência ou consentimento" (LOURO, 2017, p. 16) temos, também, as formas de escapar e resistir a esse "padrão de poder que opera através da naturalização de hierarquias territoriais, raciais, culturais e epistêmicas possibilitando a reprodução de relações de dominação” (RESTREPO; ROJAS, 2010, p. 15).

É neste diapasão de subversão e disputa que precisamos reconhecer a potência política de algumas ações para enfrentar, em especial, a nova era fascistacisheteronormativa-machista-racista que estamos a viver. Tomamos como exemplo o atualíssimo caso do editorial do jornal La Nación, publicado em $1^{\circ}$ de fevereiro de 2019, intitulado "Niñas madres con mayúsculas" (2019) $)^{5}$ que, acompanhando a reafirmação da sexopolítica heterossexual, ratifica a apologia da violação do corpo feminino, quase como um pedido de desculpas aos históricos crimes de estupro às crianças e, claro, em oposição ao movimento "los pañuelos verdes", que colocava em pauta um dos temas mais sensíveis e controversos para as sociedades latino americanas, qual seja, o direito à interrupção voluntária da gravidez. Impulsionado pela Campanha Nacional pelo "Direito ao Aborto Legal, Seguro e Gratuito", tem como lema a educação

\footnotetext{
${ }^{5}$ https://www.lanacion.com.ar/2216199-ninas-madres-con-mayusculas. Acesso em: 03/02/2019.
} 
sexual para decidir, contraceptivos para não abortar e o aborto legal para não morrer, costurando, pois, três campos importantes, o da educação, o da saúde pública e o da justiça social, além, claro, do direto a decidir sobre o próprio corpo.

Em sua matéria, o La Nación idealiza a maternidade em meninas que sequer terminaram de se formar e apela, com um conteúdo fundamentalista, a defender um ideário conservador e patriarcal que localiza garotas como criadoras e incubadoras, pensamento que caminha na contramão de um enorme movimento feminista que avança na política e na luta por seus direitos. A asseveração dessa matéria nos leva a pensar com Kleaim (2016), o que seria de nossos corpos se não fossem as marcas que nos (im)põe? Como negar a romantização da matéria e a máxima de que crianças violentadas não deveriam fazer aborto para desempenhar o papel de "mãe"? Que a gravidez na infância não está vinculada a um "instinto materno", ao contrário, é abuso sexual e, portanto, trata-se de gravidez forçada, resultado da suposta naturalidade da sexopolítica, afinal,

[...] a criança é um artefato biopolítico que garante a normalização do adulto. A polícia de gênero vigia o berço daqueles que estão para nascer para transforma-los em crianças heterossexuais. A norma faz sua ronda em torno de corpos frágeis. Se você não for heterossexual, é a morte que o espera. A polícia de gênero exige características diferentes para o garotinho e para a garotinha. Ela molda os corpos para desenhar órgãos sexuais complementares (PRECIADO, 2013, s.p.),

e, com isso, queremos dizer que as práticas discursivas sobre as crianças ou sobre a infância nos remetem a construções históricas de conceitos morais que tornam natural e comum a aberrante matéria do La Nación e, como queremos argumentar contra essa "invenção da natureza"6 (SEGATI, 2018, p. 25), nos interessa pensar sobre os deslocamentos, as práticas discursivas heterotópicas que, ancoradas na produção de uma consciência minoritária, "remete[m] a potências do devir, que pertencem a uma instância diferente do domínio do poder e da representação, ao possibilitar que se escape do sistema de poder a que se pertencia como parte da maioria" (DELEUZE, 2010, p. 17).

Em reação ao editorial do La Nación, vários legisladores, profissionais de saúde, organizações sociais e trabalhadores da imprensa do próprio diário manifestaram seu repúdio através das redes sociais, em intervenções motivadoras de resistência

\footnotetext{
6 "llamé la inventión de la naturaleza, lo que Butler entendió como el caráter performativamente
} construído de las posiciones de género" (SEGATO, 2018, p. 25). 
decolonial, como podemos perceber na foto a seguir:

FIGURA 2 - Print dos autores

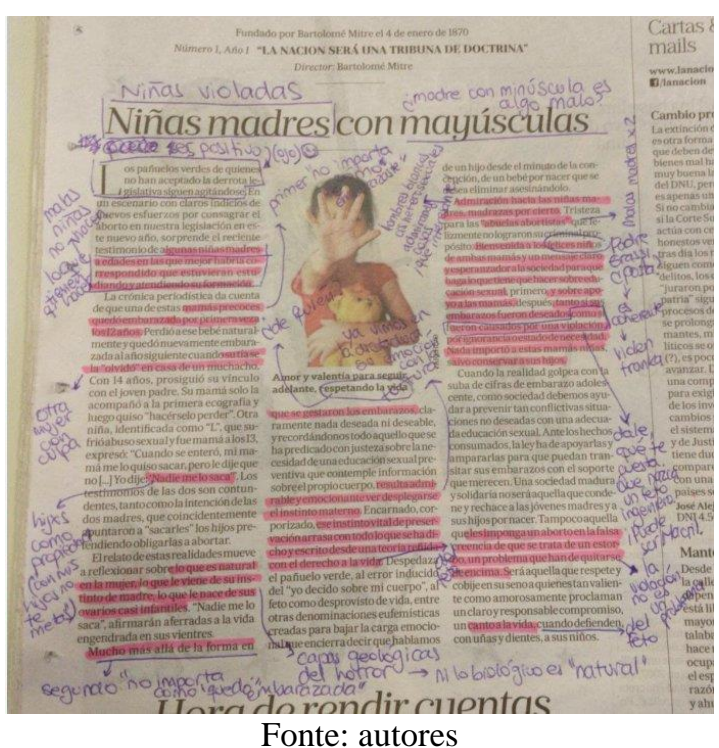

A rasura ao editorial, compartilhado pelas redes sociais, pode ser lido como prática de ativismo em rede numa clara "atitude decolonial”, que se dá, primeiro, pela mudança de olhar, pelo giro decolonial que, por meio da radicalidade própria da imagem, serve como sensibilização e conscientização de um novo tempo que se quer desessencializado, desbiologizado, um ato de desaprender para entender o mundo que se vive, uma prática social,

[...] que procura desafiar e derrubar as estruturas sociais, políticas e epistêmicas da colonialidade - estruturas até agora permanentes - que mantêm padrões de poder enraizados na racialização, no conhecimento eurocêntrico e na inferiorização de alguns seres como menos humanos (WALSH, 2009, p. 24).

Em outras palavras, intervenções críticas e políticas como essas, estariam voltadas para instabilizar e desafiar estruturas epistêmicas da colonialidade e intervir na reinvenção da vida em sociedade, já que a vida só é possível reinventada, como diria Cecília Meireles (SECCHIN, 2001).

A intervenção acima, nos leva a pensar na arte como trincheiras de resistência, capaz de instaurar novas reflexões, desconstruções e conceitos para o enfrentamento da colonização em relação à infância, já que é desde a mais tenra idade que somos submetidos às pedagogias heteronormativas que produzem meninos e meninas coerentes com a matriz de inteligibilidade, a forma pensada por Butler que estabelece uma continuidade entre sexo, gênero, desejo e prática sexual, o que confere 
inteligibilidade aos corpos que importam (BUTLER, 2007).

A “invenção da natureza” (SEGATO, 2018, p. 25) celebrada pela atual Ministra Damares Alves, quando, diante do patético vídeo em que afirmara em tom débil que "meninos vestem azul e meninas vestem rosa", consagrava sua visão arcaica sobre gênero e sexualidade, visão, aliás, que repercute na maioria da sociedade. Ao contrário do que tentaram justificar, não se tratava metáfora, mas de uma reificação histórica de normas, porque já deveríamos

[...] entender que a sexualidade envolve rituais, linguagens, fantasias, representações, símbolos, convenções... Processos profundamente culturais e plurais. Nessa perspectiva, não há nada exclusivamente 'natural' nesse terreno, a começar pela própria concepção de corpo, ou mesmo de natureza. Através de processos culturais, definimos o que é ou não - natural; produzimos e transformamos a natureza e a biologia e, consequentemente, as tornamos históricas. Os corpos ganham sentido socialmente (LOURO, 1999. p. 3).

$\mathrm{O}$ a[r]tivismo ${ }^{7}$ propriamente dito, mas também a arte, têm sido reveladores de que "não basta resistir micropoliticamente ao atual regime e que é preciso agir igualmente para reapropriar-se da força de criação e cooperação - ou seja, atuar micropoliticamente -" (ROLNICK, 2018, p. 35). Essa resistência no campo da política de produção de subjetividade e de desejo é realizada em algumas produções no campo das artes em variadas épocas, como veremos a partir de agora.

A premissa que definia a mulher pela maternidade, por exemplo, tema das duas primeiras imagens, também foi desconstruída na poesia e na ficção. Em "Uma canção desnaturada", canção da obra “A Ópera do Malandro" (1978), Chico Buarque expõe a negação e a desumanização da maternidade quando nega alguns atributos relacionados a essa condição, como o carinho, o cuidado, a proteção. Na peça teatral ${ }^{8}$, a cena se dá depois que Teresinha, que fora criada em colégio interno de freiras, se casa clandestinamente com o contraventor Max Overseas:

VITÓRIA: Minha filha, que bom que você veio! É que espalharam um boato horrível a teu respeito. Imagina que inventaram que você se casou com um contraventor! Um patife! Um pagão! Daí o teu pai ficou nervoso, e com toda a razão. Teresinha, pelo amor de Deus! Desminta logo essa falácia se você não quer matar teu pai de desgosto e tua mãe do coração (BUARQUE, Chico, 1978, cena 3, sp)

\footnotetext{
${ }^{7}$ A[r]tivismo, não é um conceito consensual, mas tem sido utilizado ao fazer referências a ações sociais e políticas, produzidas principalmente coletivos, que se valem de estratégias artísticas ou simbólicas para problematizar causas e reivindicações sociais.

${ }^{8}$ Essa música foi inserida, em 1979, na versão paulista de “A ópera do malandro".
} 
Ao confirmar a "traição" da filha, Vitória, descontente com o seu papel de mãe, canta uma das mais duras canções da obra buarquena'

Por que cresceste, curuminha

Assim depressa, e estabanada

Saíste maquiada

Dentro do meu vestido

Se fosse permitido

Eu revertia o tempo

Pra viver a tempo

De poder

Te ver as pernas bambas, curuminha

Batendo com a moleira

Te emporcalhando inteira

E eu te negar meu colo

Recuperar as noites, curuminha

Que atravessei em claro

Ignorar teu choro

E só cuidar de mim

Deixar-te arder em febre, curuminha

Cinquenta graus, tossir, bater o queixo

Vestir-te com desleixo

Tratar uma ama-seca

Quebrar tua boneca, curuminha

Raspar os teus cabelos

E ir te exibindo pelos

Botequins

Tornar azeite o leite

Do peito que mirraste

No chão que engatinhaste, salpicar

Mil cacos de vidro

Pelo cordão perdido

Te recolher pra sempre

À escuridão do ventre, curuminha

De onde não deverias

Nunca ter saído

A canção desnaturada, como o post de Juliana Reis, põe em xeque a premissa "tota mulier in útero" e revela a mentira da maternidade, que não passa de uma construção social erigida através de rituais, linguagens, fantasias, representações, símbolos e convenções que envolve processos profundamente culturais e plurais (Louro, 2000), afinal,

[...] a inscrição dos gêneros - feminino ou masculino — nos corpos é feita, sempre, no contexto de uma determinada cultura e, portanto, com as marcas dessa cultura. [...] As identidades de gênero e sexuais são,

\footnotetext{
${ }^{9}$ Inspirado em Caio F., sugerimos a audição dessa música na versão de Ithamara Koorax, em gravação de
} 1992, no álbum "Itamara Koorax - ao vivo". 
portanto, compostas e definidas por relações sociais, elas são moldadas pelas redes de poder de uma sociedade. (LOURO, 2000, p. 11).

Um e outros exemplos, realidade e ficção, o bebê em um, a adolescente no outro, são exemplos de contraordem do discurso e conduzem a leitora a reflexões importantes sobre o legado do catolicismo, que o que pregam - o normal ou a normalidade - em suas múltiplas versões, não passam de ficções sociais com efeitos performativos produzidos no interior dos regimes discursivos. É pela imposição da norma e de sua naturalização que se estabelece aquilo que será compreendido como normal, afinal, como já dissemos, "a normatividade não está assegurada, ela é promovida, experimentada cotidianamente" (LOURO, 2017, p. 22) e, que "deus não proíbe nada. Que deus é tudo aquilo que ri, que chora, que vibra, que dança, que pulsa. E que, pleno, não precisa vigiar a vida de ninguém” (THÜRLER, 2018, p. 94), porque

[...] não acredito em um Deus raivoso com o dedo apontando para mim e dizendo que sou devedor. Deus não aponta o dedo para o que está certo ou errado. Deus é um princípio que reúne infinitos universos. Deus não está preocupado com o que eu faço com o meu pau, de forma nenhuma. Isso é culpa judaico-cristã (MATOGROSSO, Ney. 2018, p. 159).

Deleuze, muitas vezes repete a frase de Antonin Artaud: “É necessário acabar de vez com o julgamento de Deus"10. O julgamento de Deus é o juízo transcendente, aquele que, por força de outra vida mais perfeita, julga esta nossa vida terrena. Em 2011, Thürler pensava sobre isso e publicou "Shortbus: um diálogo entre o corpo e a cidade - aspectos da subcultura (homo) erótica ou um pau duro não acredita em Deus!", que gostaríamos de retomá-lo para animar nossa leitura.

Quando afirmou que "um pau duro não acredita em Deus", Thürler quis fazer coro com Artaud, mas também, com o "Deus está morto", do Nietzsche. E assim como o filósofo alemão, afirmar que a influência da religião e de todos os dispositivos de controle, em nossas vidas, é cada vez menor. A igreja, os mitos, as ideias, os ritos, a moral, tudo isso está enfraquecendo e desaparecendo. Se o amor é líquido, a moral também o é. Não só a religião, mas a crença em seus valores metafísicos, a crença em verdades últimas, a crença no Bem, Belo e Verdadeiro. O que é verdade? O que é correto? E bom, no mundo contemporâneo? Não temos mais medo de Deus, ele é fraco, ele é a criação, a invenção de um povo impotente, sofredor, buscando refúgio. Deus

\footnotetext{
${ }^{10}$ Referência à transmissão radiofônica "Para acabar com o julgamento de Deus", realizada por Artaud (como autor e narrador) e por alguns de seus amigos (Roger Blin, Marie Casarès e Paule Thévenin) que o ajudaram na produção dos efeitos sonoros durante a transmissão.
} 
está morto como uma verdade eterna, como um ser que controla e conduz o mundo, como um pai bondoso que justifica os acontecimentos, como sentido último da existência Deus está morto como um grande ditador divino que exige obediência de seus servos. Ele já não é uma questão importante para se tratar, ele já não é uma pergunta para a qual procuramos respostas. "Um pau duro não acredita em Deus" provocava uma rasura no projeto colonial que durante séculos mapeou nossos corpos e decretou partes que poderiam ou deveriam ser reconhecidas como espaços legitimados de prazer. Esse processo performativo, reiterado pelos discursos religiosos, é o responsável pela longa história da supremacia masculina em contraponto à mulher obediente, mas, também, de outros projetos oriundos desse pensamento social binário e excludente, como o de que os homens só se faziam humanos através do afastamento de tudo que neles houvesse da criança,

[...] era pela luta contra o que de infância houvesse em nós que poderíamos nos alçar à humanidade e à cidadania. A infância não se confundia com ingenuidade; identificava-se com animalidade e com incapacidade: ausência de razão, de domínio linguístico e de consciência moral. Entendia-se que uma criança aprendia com o corpo e não com o intelecto, sua vontade era instintiva e não crítica; logo, faltava-lhe caráter, inteligência e competência humana (CECCIM; PALOMBINI, 2009, p. 303).

Na contramão desse entendimento, para nós, junto com G. Agamben (2005), a infância é uma condição da experiência humana, como espaço profícuo de mudanças e transformações sociais futuras, entendida mesmo como potência, por isso é preciso pensar no "torna-se adulto de uma criança", afinal,

[...] quando digo que 'uma criança se tornou adulto', quero dizer que uma criança devém adulto e entendo esse movimento dentro da lógica do ser e, nesse sentido, os dois extremos passam a ser importantes nessa frase - criança e adulto -, enquanto o que acontece no meio, no intervalo entre eles fica nebuloso, ou seja, sabemos o que são uma criança e um adulto, mas pouco ou nada sabemos a respeito do movimento envolvido nessa transformação. Estimulados por essa lógica, desejamos que as transformações sejam rápidas, porque o fundamental para a nossa sociedade não está no meio, mas nos pontos de partida e de chegada. Para expressar a vida, para não a aprisionar, seria necessário pensar alterando a frase 'a criança torna-se adulto' para 'o tornar-se adulto de uma criança', onde fazemos de um predicado um sujeito, ou onde inventamos um verbo que possa explorar essa relação, como o verbo adultizar. O importante não é se se é criança ou adulto, mas como me adultizo, por onde transito, porque o que transita é vida, porque o movimento de adultizar é um dos movimentos mais vitais que pode, através de mim, avançar (THÜRLER, 2018, p. 96). 
As crianças, cujas vozes nem sempre são valorizadas pelos adultos, apontam com o dedo em riste:

- O rei está nu!

A célebre frase do conto "As roupas novas do imperador", de Hans Christian Andersen, é evocada como um "enunciado performativo" (AUSTIN, 1990), aquele que cria a própria realidade que parece descrever, que é capaz de fazer coisas com palavras, como no clássico exemplo do padre que, ao dizer: "Eu vos declaro marido e mulher", performa (concretiza) o casamento entre duas pessoas. $\mathrm{O}$ rei nu, enunciado por uma criança, performa o absurdo da nudez do vaidoso Imperador que julgava estar vestido com uma roupa somente visível aos inteligentes, mas, também, é potente metáfora decolonial de superação da enganadora questão do universalismo ocidental, da "egopolítica del conocimiento" (GROSFOGUEL, 2007, p. 71) com a intenção de demonstrar, entre outras coisas, que não existem verdades absolutas, normas, convenções ou valores, mas, pontos de vista diversos, afinal, "assim é se lhe parece", parafraseando Pirandello que, em sua peça ${ }^{11}$, propõe uma discussão ainda mais profunda sobre a impossibilidade de se chegar a uma única verdade e que "un diálogo horizontal liberador, en oposición al monólogo vertical de Occidente, requiere de una descolonización en las relaciones globales de poder" (GROSFOGUEL, idem, p. 73).

E, por fim, resta dizer, à guisa de epílogo, que este texto insubordinado foi inspirado pelas palavras de bell hooks (2018), seu desejo de ter em mãos um texto, "um livro conciso, fácil de ler e de entender" (hooks, 2018, p. 127), sem jargão ou linguagem acadêmica que dificultam a compreensão do que, de fato, importa dizer. Foi assim que construímos essas trilhas para se pensar sobre a importância da desaprendizagem e das contra-pedagogias, (SEGATO, 2015), através de práticas intervencionistas a[r]tivistas e artísticas no mundo atual, como elas vem se constituindo em um campo de pensamento que colaboram em romper com as variadas nuances do colonialismo educando para um consciência crítica e ampliando o debate em torno das resistências micropolíticas que beneficiam a autonomia, a dignidade e a liberdade.

Recebido em: 24-02-2019 Aceito em: 11-03-2019

\footnotetext{
${ }^{11}$ Fazemos referência à peça “Assim é (se lhe parece)”, de Luigi Pirandello, escrita em 1917.
} 


\section{Referências}

AGAMBEM, Giorgio. Infância e História: destruição da experiência e origem da história. Belo Horizonte/MG: Editora UFMG, 2005.

ANDERSEN, Hans Christian. A roupa nova do imperador: recriação do clássico conto de fadas por um elenco. Trad. José Rubens Siqueira. São Paulo: Companhia das Letrinhas, 1998.

AUSTIN, J.L. Quando dizer é fazer. Porto Alegre: Artes Médicas, 1990.

BEAUVOIR, Simone. O segundo sexo: fatos e mitos. São Paulo: Difusão Europeia do Livro, 1960.

BUTLER, Judith. Prefácio. In: SABSAY, Leticia. Fronteras sexuales - espacio urbano, cuerpos e ciudadanía. $1^{\mathrm{a}}$ ed. Buenos Aires: Paidós, 2011.

BUTLER, Judith. El Género en disputa. El feminismo y la subversión de la identidad. Trad. de Maria, Antonia Muñoz. Barcelona: Paidós Ibérica, 2007.

CAVALCANTE, Rebeca Freitas. Ciberativismo: como as novas formas de comunicação estão a contribuir para a democratização da comunicação. Dissertação. Universidade Nova de Lisboa, 2010.

CECCIM, Ricardo Burg; PALOMBINI, Analice de Lima. Imagens da infância, devircriança e uma formulação à educação do cuidado. Revista Psicologia \& Sociedade; 21, pp 301-312, 2009.

DELEUZE, Gilles. Sobre o teatro: um manifesto a menos. Rio de Janeiro: Jorge Zahar Editores, 2010.

GROSFOGUEL, Ramón. Descolonizando los universalismos occidentales: el pluriversalismo transmoderno decolonial desde Aimé Césaire hasta los zapatistas. In: CASTRO-GÓMEZ, Santiago; GROSFOGUEL, Ramón. El giro decolonial: reflexiones para una diversidad epistémica más allá del capitalismo global. Bogotá: Siglo del Hombre Editores; Universidad Central, Instituto de Estudios Sociales Contemporáneos y Pontificia Universidad Javeriana, Instituto Pensar, 2007.

GROSFOGUEL, Ramón. Descolonizar as esquerdas ocidentalizadas: para além das esquerdas eurocêntricas rumo a uma esquerda transmoderna descolonial. Dossiê Saberes Subalternos. Contemporânea - Revista de Sociologia da UFSCar, 2012.

HOLLANDA, Chico Buarque. Ópera do malandro. São Paulo: Círculo do Livro, 1978.

HOOKS, Bell. O feminismo é para todo mundo. Trad. Ana Luiza Libânio. 1. ed. Rio 
de Janeiro: Rosa dos Tempos, 2018.

KLEAIM, Luiz Cláudio. Prefácio. In: RODRIGUES, Alexsandro, MONZELI, Gustavo Artur, FERREIRA, Sérgio Rodrigo da Silva (Orgs.). A política do corpo: gêneros e sexualidades em disputa. Vitória: EDUFES, 2016.

LOURO, Guacira Lopes. O corpo educado: pedagogias da sexualidade. Belo Horizonte: Autêntica, p. 9-34, 1999.

LOURO, Guacira Lopes. O Corpo Educado: pedagogias da sexualidade. Belo Horizonte: Autêntica, 2000.

LOURO, Guacira Lopes. Gênero, sexualidade e educação: uma perspectiva pósestruturalista. Petrópolis: Vozes, 2007.

LOURO, Guacira Lopes. Os Estudos Queer e a Educação no Brasil: articulações, tensões, resistências. Contemporânea. Dossiê Saberes Subalternos, 2012.

LOURO, Guacira Lopes. Flor de açafrão. Takes Cuts Close-ups. Belo Horizonte: Autêntica Editora, 2017.

MATOGROSSO, Ney. Ney Matogrosso - Vira-lata de raça. Pesquisa, interlocução e organização: Ramon Nunes Mello. São Paulo: Tordesilhas, 2018.

NASCIMENTO, Carla. Mulher que rejeitou desafio da maternidade tem perfil no facebook bloqueado e defende: 'não é depressão'. Jornal 'O Extra', Caderno Mulher, Rio de Janeiro, 17 fev. 2016.

MIÑOSO, Yuderkys Espinosa. De por qué es necesario un feminismo descolonial: diferenciación, dominación co-constitutiva de la modernidad occidental y el fin de la política de identidade. Revista Solar, v. 12, n. 1, Lima, p.171, 2016.

MISKOLCI, Richard. O desejo da nação: masculinidade e branquitude no Brasil de fins do XIX. Annablume Editora/FAPESP, São Paulo, 2012.

PRECIADO, Paul B. La isquierda bajo la piel. Um prólogo para Suely Rolnik. In: ROLNIK, Sueli. Esferas da insurreição - notas para uma vida não cafetinada. 1 ed. São Paulo, 2018.

ROLNIK, Sueli. Quem defende a criança queer? Trad. de Fernanda Nogueira, 2013. Disponível em: https://blogueirasfeministas.com/2013/01/24/quem-defende-a-criancaqueer/. Acesso em: 04 fev. 2019.

REIS, Juliana. Disponível em: https://delas.ig.com.br/comportamento/2016-0308/juliana-reis-detestar-ser-mae-pessoas-pediram-desculpa.html, 2016. Acesso em: 30 dez. 2018.

RESTREPO, Eduardo; ROJAS, Axel. Inflexión decolonial: fuentes, conceptos y cuestionamientos. Instituto de Estudios Sociales y Culturales Pensar Maestría en Estudios Culturales, Universidad Javeriana. Editorial Universidad del Cauca: Popayán, Colombia, 2010. 
ROSSET, Clemént. O princípio de crueldade. Rio de Janeiro. 1989.

SECCHIN, Antônio Carlos. Poesia Completa: Cecília Meireles, vol. 1 e 2. Rio de Janeiro: Nova Fronteira, 2001.

SEGATO, Rita. A base política das relações de violência de gênero. Entrevista com a antropóloga Rita Segato, 2017. Disponível em: http://www.ihu.unisinos.br/78-

noticias/570524-a-base-politica-das-relacoes-de-violencia-de-genero-entrevista-com-aantropologa-rita-segato. Acesso em: 29 jan. 2019.

SEGATO, Rita. Contra-Pedagogías de la crueldade. 1. ed. Cidade Autonôma de Buenos Aires: Prometeo Libros, 2018.

SEGATO, Rita. Las nuevas formas de la guerra y el cuerpo de las mujeres. Dossiê Sociedade e Estado, v. 29, n. 2, Brasília, mai/ago/2014. Disponível em:

http://www.scielo.br/scielo.php?script=sci_arttext\&pid=S0102-69922014000200003. Acesso em: 29 jan. 2019.

TREVISAN, João Silvério. Devassos do paraíso: a homossexualidade no Brasil, da colônia à atualidade. 7. ed. Rio de Janeiro: Record, 2007.

THÜRLER, Djalma. "Sabedoria é desaprender" - notas para a construção de uma política cultural das margens. In: SILVA, Gimima; PUGA, Lúcia; RIOS, Otávio (Orgs.). Alfabetização política, relações de poder e cidadania: perspectivas interdisciplinares. 1. ed. Rio de Janeiro: Letra Capital, 2018a.

THÜRLER, Djalma. Da filosofia como modo superior de dar oet: arte, violência e censura em tempos de cólera. In: MONTEIRO, Lorena Madruga; SANTANA, Luciana Santana (Orgs.). Temerosas transações: ensaios sobre o golpe recente no Brasil [recurso eletrônico]. Cruz do Sul: Essere nel Mondo, 2018.

THÜRLER, Djalma. Crítica cultural e educação básica: diagnósticos, proposições e novos agenciamentos. In: SANTOS, Cosme Batista dos; GARCÍA, Paulo César Souza; SEIDEL, Roberto Henrique (Orgs.). Crítica cultural e educação básica: diagnóstico, proposições e novos agenciamentos. São Paulo: Cultura Acadêmica, 2011.

WILDE, Oscar. O retrato de Dorian Gray. Trad. Marcela Furtado. São Paulo: Ed. LandMark, 2012.

WALSH, Catherine. Interculturalidade Crítica e Pedagogia Decolonial: In-surgir, reexistir e re-viver. In: CANDAU, Vera Maria. Educação intercultural na América Latina: entre concepções, tensões e propostas. Rio de Janeiro: 7 letras, p. 12-42, 2009. 